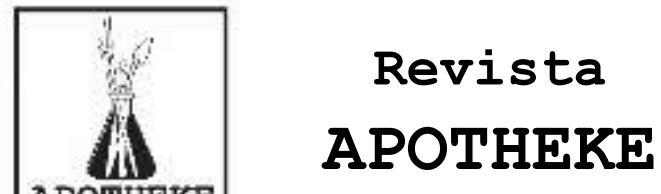

\section{Chamas e Manchas}

Talita Gabriela Robbes Esquivel

\section{Resumo}

O presente texto consiste no memorial descritivo dos trabalhos realizados na disciplina Meios de Produção e Práticas Híbridas, ministrada pelo Prof. Dr. Agnus Valente, do curso de Pós-Graduação em Artes da UNESP, adaptado para participação na Jornada de pesquisa da UNESP, com o título Manchas de calor, com pequenas alterações para esta publicação da Revista Apotheke. Trata-se de trabalhos realizados por meio da queima, em forno à lenha, de manequins plásticos sobre suportes de metal. A produção girou em torno do calor e do formato do corpo, resultando em manchas nas placas de metal. O texto, em ordem cronológica, foca no processo criativo e abrange a produção física dos trabalhos e seus resultados. Isto é, discorre sobre o modo como foram feitos e sobre os resultados visuais dos trabalhos.

Palavras-chave: Queima; Mancha; Hibridismo.

Os trabalhos em pintura, em geral, mesmo se tratando de uma única linguagem como resultado final, possui o hibridismo em seu processo, podendo envolver desenhos, projetos, maquetes, fotografias, montagens, colagens, leituras, escritas, pesquisas, dentre outros. Também, a própria linguagem pictórica pode ser considerada híbrida, mesmo de forma sutil, ao envolver o desenho e a pintura em sua linguagem.

o conceito de hibridismo me chamou a atenção já no início das aulas da disciplina ao tomar conhecimento de sua terminologia. A origem do termo híbrido envolve uma história de dominação, violência e miscigenação. Os filhos gerados pelo estupro dos invasores de uma nação tinham suas mães pertencentes à pátria dominada e seus pais como os dominadores da nação na qual nasceram. A mãe, violentada, 


\section{A Revista}

sofria pelo preconceito e destruição do lar, e o filho, hybris, uma mistura entre as duas pátrias, tornava-se uma ameaça às duas. Logo, o híbrido é um ser sem lugar, monstruoso e ameaçador. A mistura violenta e dominadora vem do grego hybris, algo que não deveria ter ocorrido. Já a origem latina hibrida tem sua miscigenação gerada de forma mais natural, sem violência, com as famílias formadas na nova pátria.

Se pensarmos em um caso de extremo oposto, sem qualquer existência híbrida, como, por exemplo, na formação de casais dentro de uma mesma família, essa prática gera filhos com degeneração genética. Portanto, tanto o híbrido quanto o "puro" tornam-se seres sem lugar, considerados monstruosos. O trabalho artístico híbrido, na atualidade, apesar de ter uma maior aceitação, tem muito dessa carga de rompimento das regras, de não lugar e, por vezes, de violência.

A proposta de trabalho para a disciplina partiu do conceito de híbrido e da busca por características pictóricas, com a utilização de materiais não convencionais. Foram formulados projetos de experimentações, em formato de esboços, com a mescla de um meio sólido e outro maleável.

Devido a própria curiosidade quanto aos materiais, realizei um experimento a partir do derretimento de plástico em um suporte de metal. A ideia era criar uma superfície bidimensional, tendo no plástico derretido um efeito similar à plasticidade da tinta.

Em um primeiro teste foi utilizado um soprador térmico para derretimento de uma garrafa plástica. Neste experimento, o plástico se contorceu, gerando uma nova forma. Isso ocorreu devido à pequena saída de ar, que fez com que o calor se concentrasse em uma pequena região. 


\section{Revista
APOTHEKE}

Logo, ficou perceptível que o soprador térmico não traria os resultados pretendidos e foi pensada outra opção de derretimento.

Desde o momento em que decidi trabalhar com plástico derretido, senti a necessidade de inserir a imagem do corpo. Uma solução seria moldar o formato de um corpo enquanto o plástico derretido estivesse ainda quente sobre a superfície. Porém, outra ideia me pareceu mais atrativa, usar manequins de plástico para o derretimento. Estas foram as perspectivas iniciais, que não podiam prever os resultados que viriam a seguir.

Um fato importante a ser colocado foi o auxílio constante do técnico luís e, por vezes, do estagiário da marcenaria, Gustavo, além da ajuda de colegas durante o processo, como Alexandre Gomes Vilas Boas, que contribuiu com o registro fotográfico do processo. Já para resolver o problema do derretimento do plástico, tive a ajuda de outro colega, o que será discorrido a seguir.

Para realizar o derretimento do plástico de forma igual em todo o objeto, e ainda, tratando-se de um manequim, que possui um plástico relativamente grosso, seria necessária a utilização de um forno. O mesmo poderia ser construido a partir dos tijolos que estavam no estacionamento do Campus da UNESP, próximo à marcenaria. Era necessária a ajuda de alguém que entendesse da construção de fornos e lembrei-me do colega de curso, Kleber da Silva, cuja pesquisa é justamente sobre a construção de fornos de alta temperatura e baixo custo. 

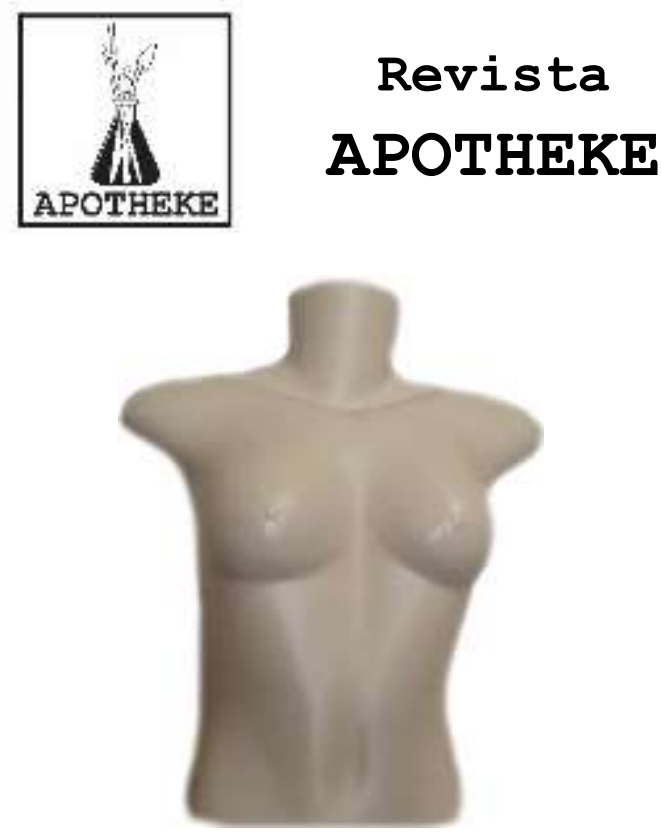

Figura 1: Torso de manequim usado para a primeira queima.

Foi iniciada a construção do forno com a ajuda e orientação do Kleber. Rapidamente, o forno à lenha estava preparado. O manequim de plástico foi colocado sobre uma placa de ferro e alocado dentro do forno. Em seguida, o fogo foi aceso e todo o cuidado foi tomado para que não houvesse qualquer perigo (ver figura 2).

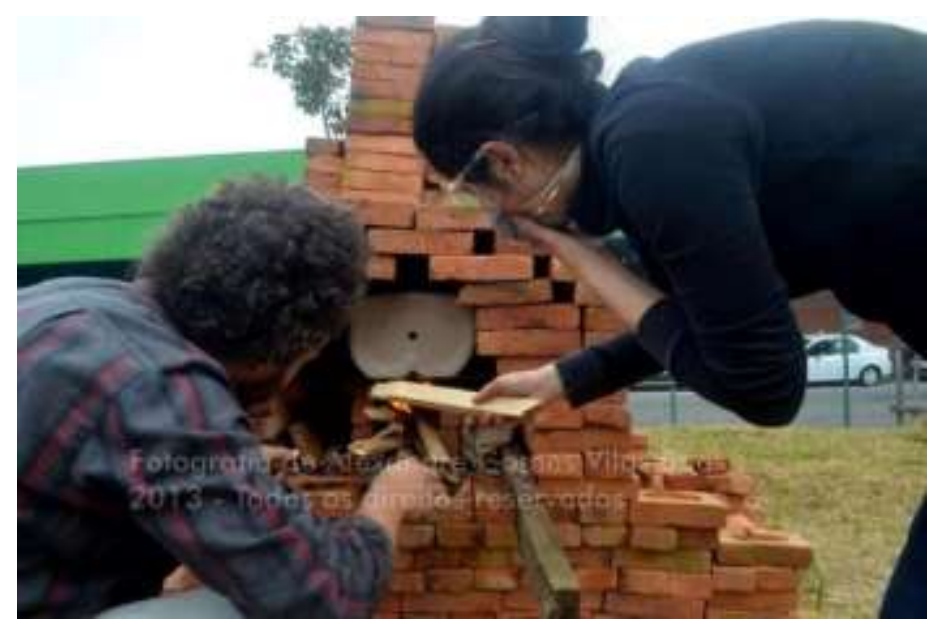

Figura 2: Após a montagem do forno, início da queima.

Este primeiro trabalho teve um resultado inesperado. 0 manequim derreteu e rebaixou de forma igual sobre a superfície do ferro, conforme desejado. Porém, as cores que surgiram ao redor, devido à queima, foram inesperadas. Um forte azul, e também amarelos e vermelhos surgiram ao redor do plástico derretido, que já não continha mais os 


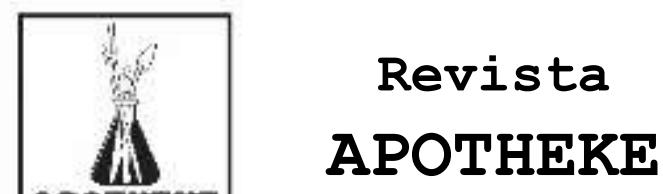

atributos do manequim, restando apenas os contornos (figura 3).

Foi realizada a tentativa de uma pequena intervenção sobre o plástico derretido no metal, antes de resfriar. Porém, mesmo quente, não era possível movimentar seu material, que era a intenção inicial, pois restava firme sobre a superfície.

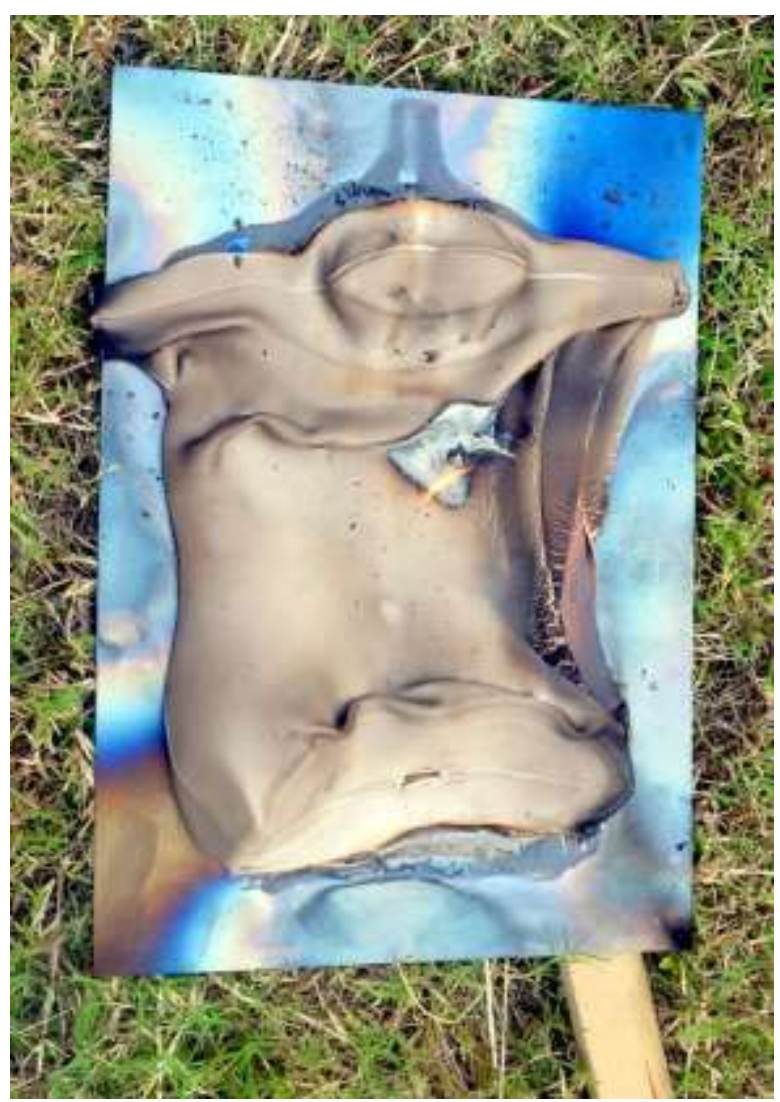

Figura 3: Manequim queimado sobre a placa de ferro, logo após a queima.

Enquanto o plástico derretido resfriava, percebi que se descolava aos poucos da placa. A alteração de tamanho dos materiais ao resfriarem impediu a aderência no metal, até que, em certo momento, ele se soltou da superfície. A breve decepção transformou-se em uma agradável surpresa. Com a retirada do plástico, foram descobertas as marcas, manchas e cores que estavam antes escondidas. 


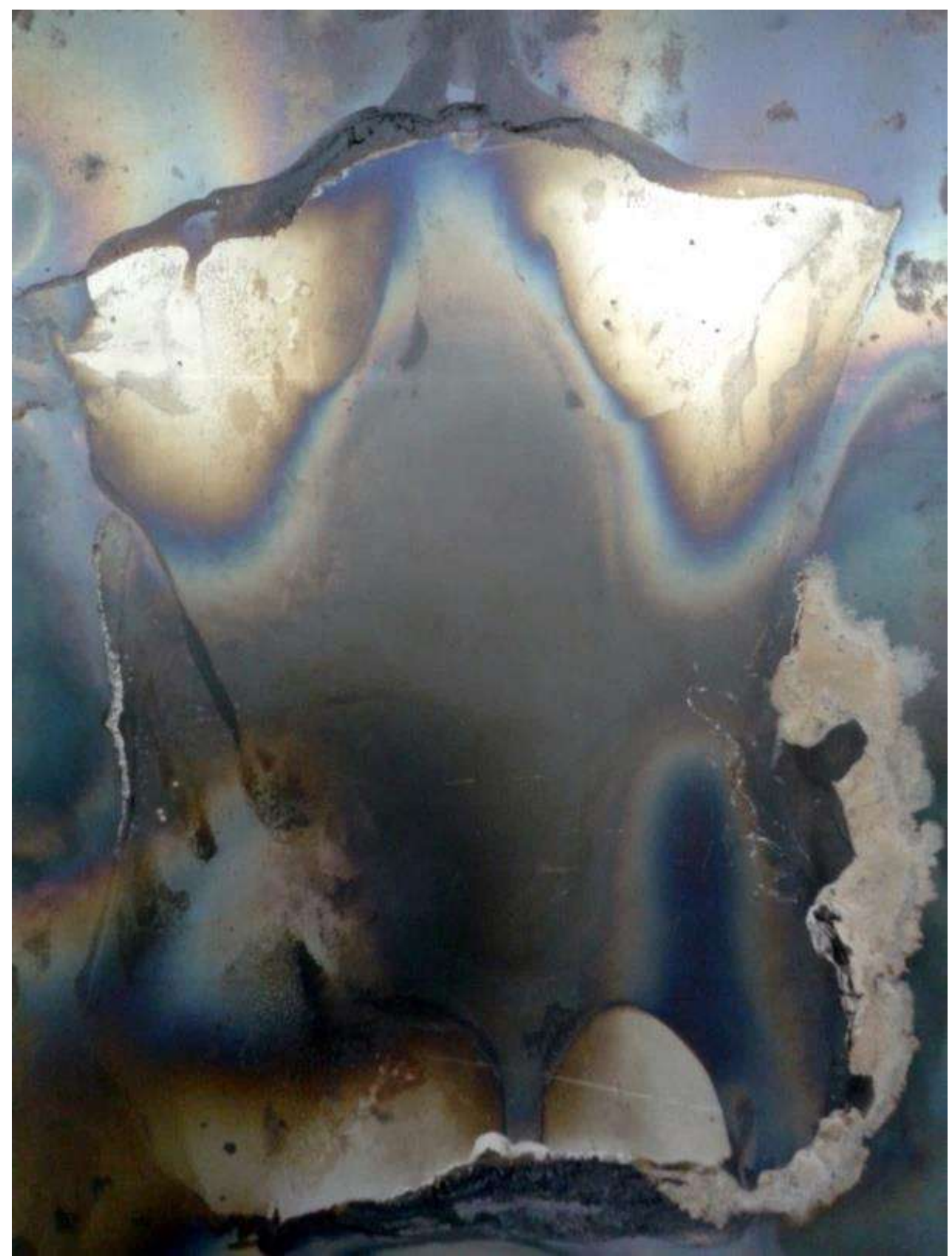

Figura 4: Resultado da primeira queima - placa de ferro após descolamento do plástico derretido.

O formato do forno permitia a passagem do fogo embaixo da placa e ao redor do manequim. Isso fez com que se formassem zonas de calor nos espaços onde o manequim não tocava o suporte, como na altura da cintura e no meio das costas. Os tons azuis fortes, surgidos quando a placa ainda estava quente, ficaram mais fracos. Neste momento havia 


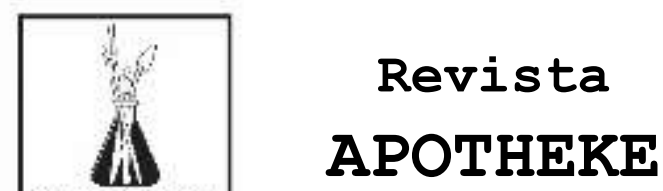

outras zonas de cores, manchas em tons pretos, azuis, vermelhos e amarelos, que seriam permanentes à placa. Isto é, suas cores poderiam se modificar apenas sob uma nova queima. Em seguida, envernizei a placa para protegê-la da ferrugem.

A pintura, neste trabalho, envolve o conceito de campo ampliado, termo desenvolvido por Angélica de Moraes (2005) na exposição Pintura Reencarnada. Angélica de Moraes observa que a pintura se expandiu. Não está mais apenas em seu suporte convencional e passou a usar instrumentos não tradicionais. Todo o conhecimento acerca da pintura é utilizado em outros meios, como em instalações, vídeos, fotografias e objetos, passando estes a serem considerados também pintura, por apresentarem suas características. A pintura possui aspectos exclusivos, tais como cor, mancha, plasticidade, textura, transparência, empasto e camadas, assim como na gravura, por exemplo, há a reprodutibilidade e no vídeo, o movimento. Dessa forma, a intenção de trabalho na disciplina se direcionou para a exploração de características pictóricas por meio da queima de manequins de plástico sobre metal.

A segunda queima foi realizada sobre uma placa de metal que antes constituía a porta de um armário. Desta vez, o manequim era um torso masculino e estava dividido ao meio na vertical. No momento da queima, seu contorno ficou encostado na placa, fechando a superfície. Dessa forma, não ocorreram os espaços de calor como na queima anterior, mas surgiram manchas dentro do contorno do manequim.

o resultado deste trabalho (ver figura 5) foi diferente do anterior, pois além das manchas vermelhas e azuis, formou-se uma camada pelo excesso da queima do plástico, uma espécie de crosta, firme, porém de fácil remoção. Retirei grande parte dessa crosta preta, que 


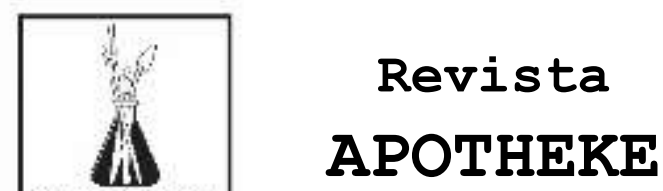

cobria quase todo o interior do formato do torso, permanecendo apenas a camada mais firme, como pode ser visto na parte superior e inferior.

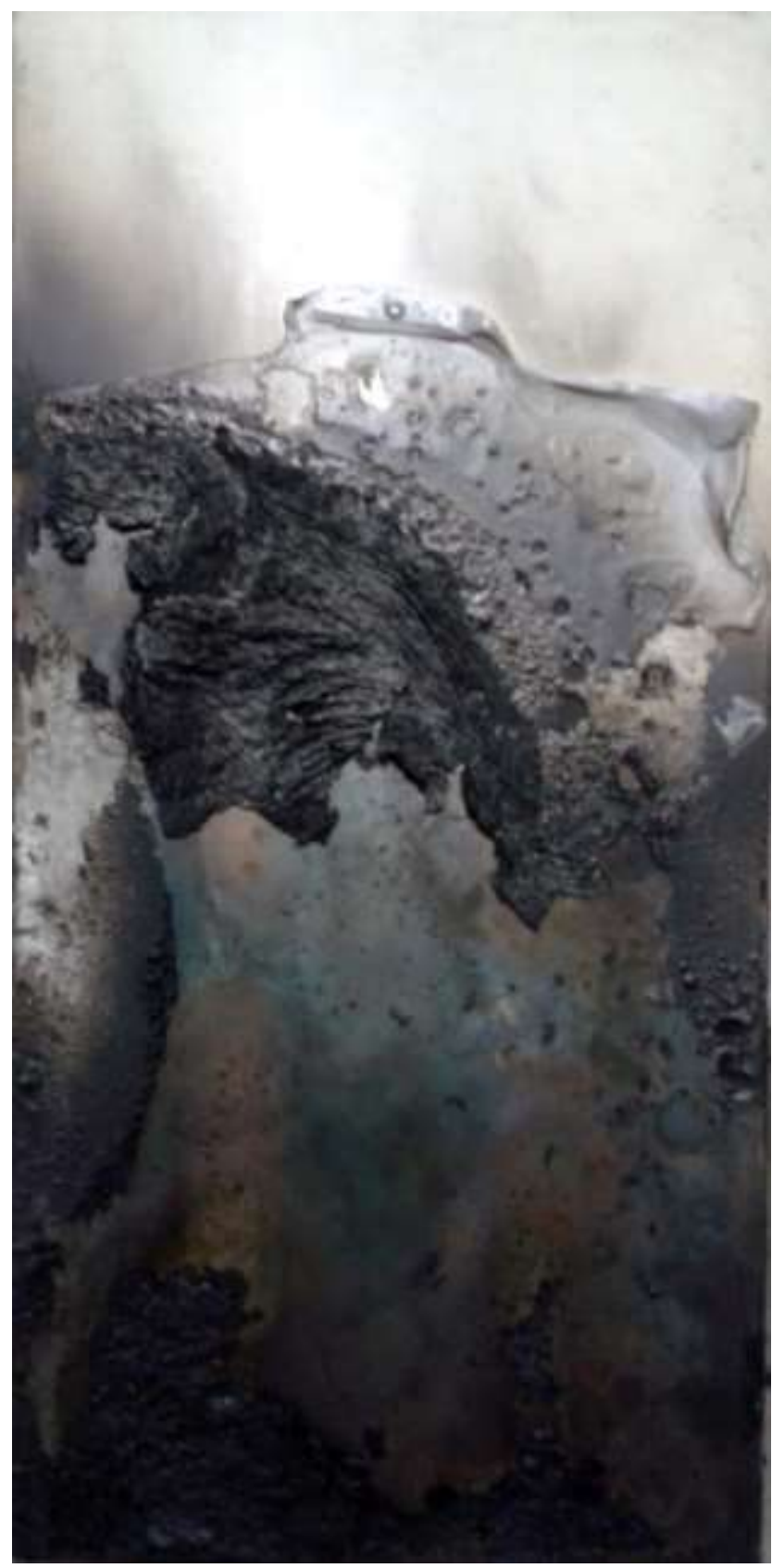

Figura 5: Segunda queima, manequim sobre metal ferroso.

Novas placas de ferro foram adquiridas para a continuação das queimas. Dessa vez, tiveram que ser cortadas, ou melhor, desbastadas, o que exigiu grande empenho no manuseio da máquina. Realizei mais duas queimas 


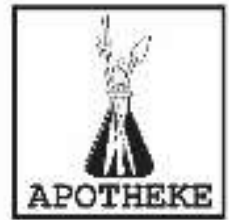

Revista

APOTHEKE

de manequim, que resultaram em um derretimento no qual o plástico aderiu à superfície. Na primeira, foi utilizado um torso feminino de um manequim cor laranja.

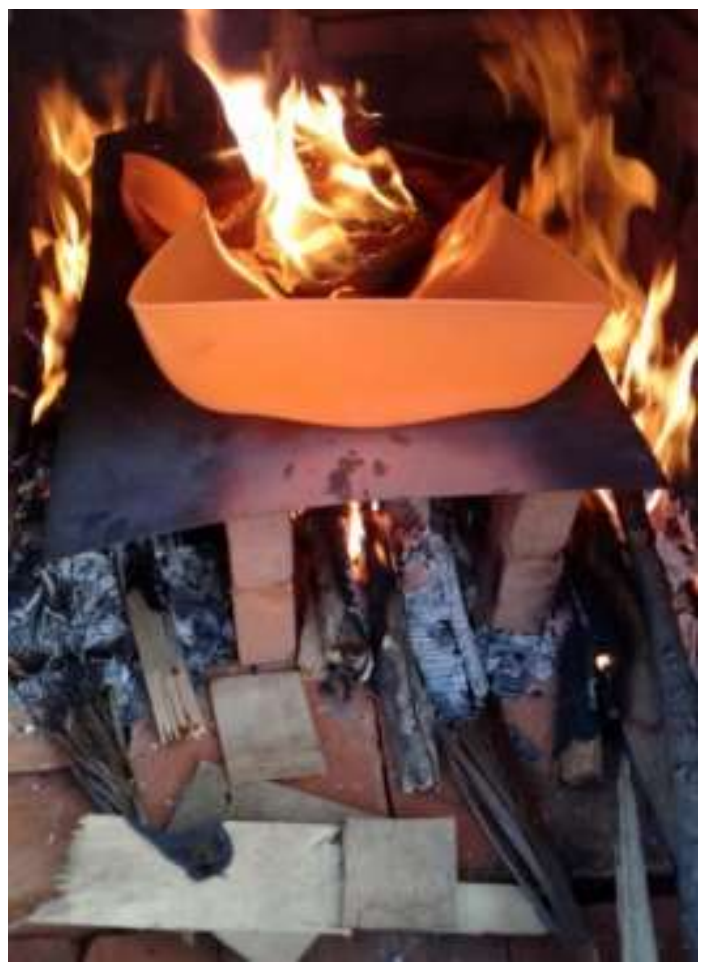

Figura 6: Queima número 3. Torso de manequim laranja sobre placa de ferro.

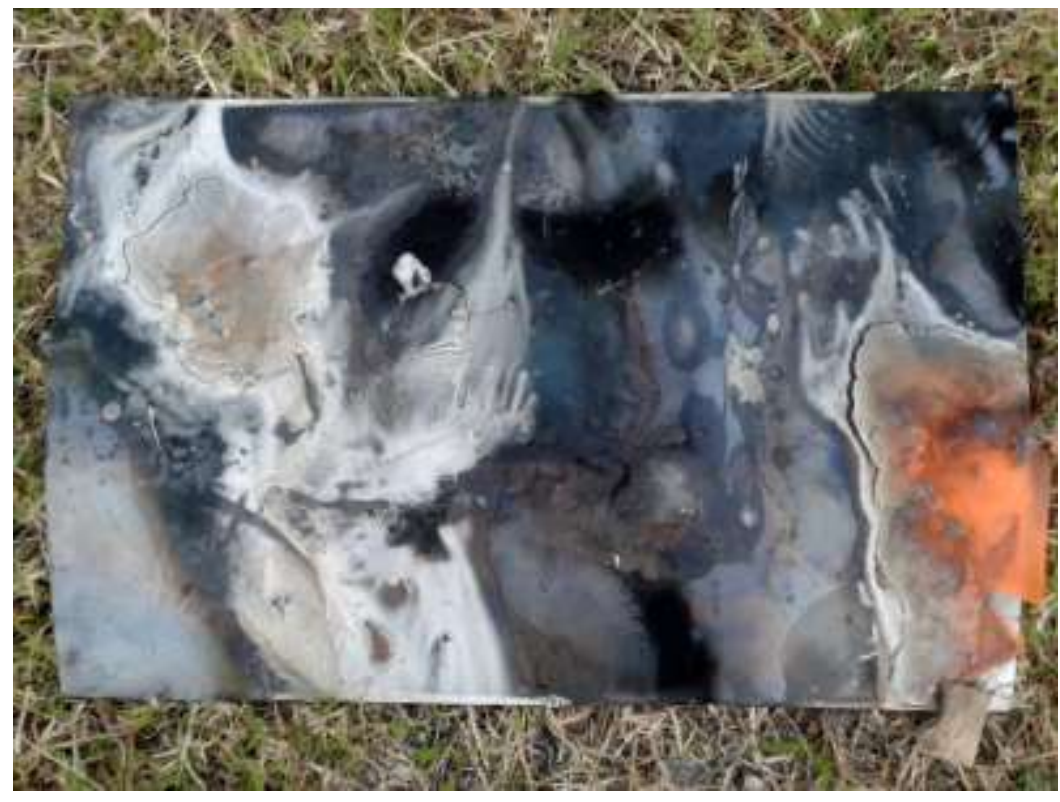

Figura 7: Resultado da queima número 3.

Apesar de tratarem-se dos mesmos materiais utilizados anteriormente, ou seja, manequim de plástico sobre placa de 


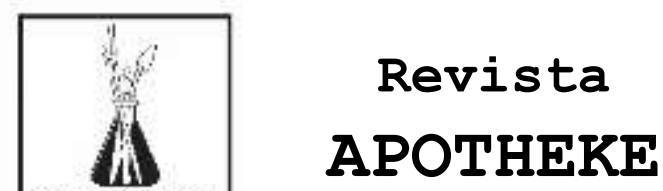

ferro, cada queima trouxe um resultado diferente. Na primeira (figura 4), formaram-se manchas e cores na superfície de ferro, sem a presença do plástico, que descolou; na segunda (figura 5), feita sobre uma antiga porta de armário, também de ferro, formou-se uma crosta preta, pelo excesso de exposição ao calor, e as manchas de cores ocorreram de modo diferente da primeira; já na terceira queima (figura 7), o resultado inclui o plástico derretido, elemento responsável pelas cores. Neste último, - plástico não descolou do metal, provavelmente devido ao excesso de calor, como podemos ver na figura 6. Formaram-se rachaduras e manchas, de pretos, brancos e laranjas em um resultado visivelmente pictórico. Após este trabalho, realizei a última queima de manequim de plástico, a partir do torso feminino um pouco maior, desta vez sobre metal galvanizado.

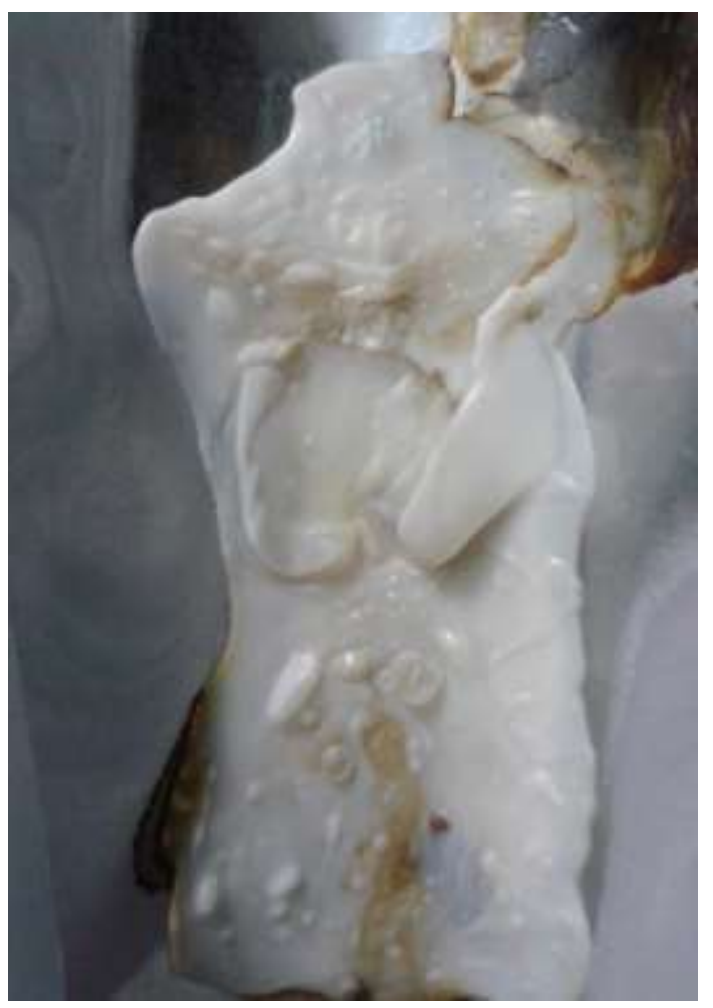

Figura 15: Resultado da queima número 4, manequim de plástico branco sobre placa de metal galvanizado. 


\section{A Revista}

Por se tratar de outro tipo de metal, o plástico aderiu à superfície formando uma área de grossa textura. Embora não tenham surgido os coloridos, proporcionados pelas placas ferrosas, algumas cores podem ser identificadas, tais como os marrons, brancos e metálicos. Durante a queima, a placa galvanizada se contraiu formando uma curva côncava, que se acentuou com o resfriamento do plástico. Assim como o anterior, este é um trabalho que pretendo retomar.

Apenas para acrescentar alguns detalhes sobre este processo de queima, os manequins algumas vezes pegavam fogo. Durante o processo das queimas, houve vários descobrimentos, que vão desde como fazer um forno à lenha de alta temperatura, como reage a queima de plástico sobre diferentes tipos de metais, como cortar e desbastar a placa de metal, até como apagar o fogo do plástico, abafando a superfície. Máscaras e óculos de proteção foram utilizados em todo o processo.

Esse processo de trabalho foi muito importante para mim, pois iniciei a pesquisa que será desenvolvida no doutorado. Na marcenaria, realizei um processo intenso de trabalho, com resultados que sugeriram uma continuação, não apenas quanto ao uso dos materiais, mas a partir de determinadas imagens, tais como costas, coluna e ossos. A disciplina abriu um leque de possibilidades para novas investigações e pretendo seguir o desenvolvimento dos trabalhos e das ideias surgidas no processo.

\section{Referências bibliográficas}

BAJTIN, Mijail. La cultura popular en la Edad Media y en el Renacimiento. Alianza Editorial, S.A, Madrid, 1987.

CEIA, Carlos. Dicionário de termos literários: híbrido. Disponível

em:

http://www.edtl.com.pt/index.php?option=com_mtree\&task=view link\&link_id=240\&Itemid=2. Acesso em: agosto de 2014 . 
CostA, Cláudia Cristina. Corpos Híbridos: a construção do corpo humano na modernidade a partir da arte e da tecnologia. Dissertação de Mestrado. Curitiba: UTFPR, 2009. Disponível em: http://repositorio.utfpr.edu.br/jspui/bitstream/1/170/1/CT PPGTE_M_Costa2c\%20Claudia20Cristina_2009.pdf. Acesso em: agosto de 2014 .

FREUD, S. O estranho. Edição standard brasileira das obras psicológicas completas de Sigmund Freud, Vol. XVII, páginas 273-318. Rio de Janeiro: Imago, 1976 (Trabalho original publicado em 1919).

KAYSER, Wolfgang. O grotesco: configuração na pintura e na literatura. $1^{a}$. ed. São Paulo: Perspectiva, 2003.

MORAES, Angélica de. Pintura reencarnada. São Paulo: Imprensa Oficial do Estado de São Paulo: Paço das Artes, 2005 .

MORAES, Eliane Robert. O corpo impossível: a decomposição da figura humana de Lautréamont a Bataille. São Paulo: Iluminuras, 2012.

SyLVESTER, David. Entrevistas com Francis Bacon: a brutalidade dos fatos. Tradução: Maria Teresa Resende Costa. São Paulo: Cosac \& Naify Edições Ltda, 1995.

VALENTE, Agnus. ÚTERO portanto COSMOS: Hibridações de Meios, Sistemas e Poéticas de um Sky-Art Interativo. 2008. 237p. Tese (Doutorado em Artes Visuais) Escola de Comunicações e Artes da Universidade de São Paulo, 2008. Disponível em: http://www.teses.usp.br/. Acesso em: agosto de 2014. 